\title{
Hallyu and Archives of Plastic Surgery
}

\author{
Yong-Ha Kim
}

Editor Emeritus, Archives of Plastic Surgery

Department of Plastic and Reconstructive Surgery, Yeungnam University, College of Medicine, Daegu, Korea

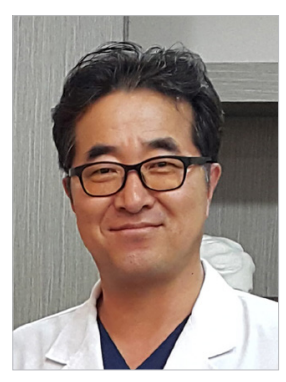

The US weekly magazine Time selected BTS as the entertainer of the year on December 10, 2020 and described the reason for doing so as follows: "In an era marked by so much anguish and cynicism, BTS has stayed true to their message of kindness, connection and self-acceptance" [1]. The music of BTS is a great comfort in the current era of coronavirus disease 2019 (COVID-19). The term Hallyu, or the Korean wave, is spreading all over the world. BTS is at the forefront of the Korean wave. Hallyu culture is rapidly spreading to the world beyond Asia, and is moving from the periphery of world culture to the center. The core of the Korean wave started with popular culture such as music, movies, and dramas. However, in a broad sense, it refers to a cultural phenomenon in which the overall culture of Korea, including fashion, cosmetics, food, tourism, dance, martial arts, and industry, is gradually becoming known throughout the world. One pillar of the Korean wave is plastic surgery [2,3].

The Korean Society of Plastic and Reconstructive Surgeons (KSPRS) has been in charge of the Hallyu of plastic surgery and has presented outstanding surgical and research results to the world. In 2015, the Washington Post stated that "South Korea is the plastic surgery capital of the world" $[3,4]$. Geopolitically, Korea is located at the center of the intersection of lines connecting the United States, Japan, China, and Central Asia to the east and west, and Russia, Southeast Asia, India, and the Middle East to the north and south. Many patients from all over the world have visited Korea to undergo cosmetic or reconstructive surgery, and at the same time, many Korean plastic surgeons have visited other countries to participate in surgery and academic exchanges and contribute to the development of plastic surgery. The KSPRS hosts PRS Korea, which is one of the world's largest academic conferences in this field (following American Society of Plastic Surgeons [ASPS], which is held in the United States) and has been a major success, with the participation of many international researchers [5].

In my previous role as editor-in-chief Archives of Plastic Surgery (Arch Plast Surg, APS), I have hoped to translate this atmosphere of the Hallyu of plastic surgery into academic achievements. We have tried to improve the quality of APS, while establishing a fair and well-structured system. Numerous researchers have invested considerable energy into these efforts, and some tangible results have been obtained. As the citation index of APS increased and the journal achieved international awareness, APS recently rose to the top tier among Asian journals in the field of surgery. However, the upward momentum has declined since last year; we have not achieved as high of a citation index as we had hoped, and APS has yet to be indexed in Science Citation Index Expanded (SCIE).

There is a long way to go.

In order to raise the quality of the journal to the next level, it is important for us to pay close attention to its foundations.

What is the purpose of an academic journal? According to Henry Oldenburg, the first editor of the Royal Society's Philosophical Transactions, the purpose of an academic journal is to give researchers a venue to "impart their knowledge to one another, and contribute what they can to the Grand design of improving natural knowledge, and perfecting all Philosophical Arts, and Sciences" [6].

Correspondingly, we may ask: what is the purpose of our journal, APS? “...APS aims to be the leading forum for communications of techniques related to Asian patients' needs... to be the 
main forum for communication among the plastic surgery scholars and clinicians of the Asia-Pacific region and beyond, and the main voice presenting this group's technical innovations to an international audience" [7].

Asians constitute a physically and socially distinctive segment of humanity. Asia is the largest and most populous continent on Earth, where $60 \%$ of the world's population lives. For plastic surgeons who aim to improve small but noticeable differences through surgery or procedures, it is important to have a thorough knowledge of the subtle differences among races in characteristics of the skin, skeleton, and facial structures. Racial, cultural, and social differences should be understood and considered in order for surgery to yield the most satisfactory results possible. Currently, the main journals in the plastic surgery field are from the United States and Europe. Those journals publish research on anatomical and surgical procedures centered on Caucasians, and there is relatively little diversity in terms of people and cultures from other continents. Furthermore, there are no SCIE-listed international journals from Asia in the field of plastic surgery. A key voice is needed to present the Asian-Pacific region's technical innovations to an international audience.

I hope that APS will be the first SCIE-indexed plastic surgery journal in Asia, and that APS will translate the enthusiasm and merits of the Hallyu of plastic surgery into a tangible academic legacy. Likewise, I hope that APS will contribute to improving knowledge and perfecting the sciences, in the spirit of Henry Oldenburg. I look forward to APS becoming the main forum for communication among plastic surgery researchers and clinicians from the Asia-Pacific region, in the spirit of kindness, connection, and self-acceptance.

\section{NOTES}

\section{Conflict of interest}

YHK, an Editor Emeritus of the Archives of Plastic Surgery, is the author of this article. However, he played no role whatsoever in the editorial evaluation of this article or the decision to pub- lish it. Except for that, no potential conflict of interest relevant to this article was reported.

\section{ORCID}

Yong-Ha Kim

https://orcid.org/0000-0002-1804-9086

\section{REFERENCES}

1. Bruner R. Entertainer of the year-BTS [Internet]. New York, NY: Time; c2020 [cited 2021 Jan 8]. Available from: https://time.com/entertainer-of-the-year-2020-bts/.

2. Kim KS. Into a global future with our members to serve the people. Arch Plast Surg 2019;46:99-101.

3. Kim YH. Changes and directions of craniofacial surgery in Korea. Arch Craniofac Surg 2019;20:281-3.

4. Swanson A. Stunning photos show why S. Korea is the plastic surgery capital of the world [Internet]. Washington, DC: The Washington Post; c2015 [cited 2021 Jan 8]. Available from: http://www.washingtonpost.com/news/wonkblog/ wp/2015/05/16/stunning-photos-show-why-south-koreais-the-plastic-surgery-capital-of-the-world/.

5. Chang DW. Plastic Surgeons of Korean Heritage: why it matters to me. Arch Plast Surg 2019;46:1-2.

6. Wikimedia. Academic journal [Internet]. San Francisco, CA: Wikimedia Foundation, Inc.; c2020 [cited 2021 Jan 8]. Available from: https://en.wikipedia.org/wiki/Academic journal.

7. Archives of Plastic Surgery (APS). Aims and scope [Internet]. Seoul: APS; 2020 [cited 2021 Jan 8]. Available from: https://www.e-aps.org/about/.

Correspondence: Yong-Ha Kim

Department of Plastic and Reconstructive Surgery, Yeungnam University College of Medicine, 170 Hyeonchung-ro, Nam-gu, Daegu 42415, Korea

Tel: +82-53-620-3481, Tel: +82-53-626-0705, E-mail: yhkim@med.yu.ac.kr

Received: December 22, 2020 • Revised: December 24, $2020 \bullet$ Accepted: December 25, 2020

pISSN: 2234-6163 • elSSN: 2234-6171

https://doi.org/10.5999/aps.2020.02551 • Arch Plast Surg 2021;48:1-2 